\title{
Gestión clínica en cirugía. Desafíos para Directores de Departamento y Jefes de Servicio
}

\author{
Clinical management in surgery. A challenge
}

La actividad quirúrgica, al igual que otras especialidades, ha sufrido un profundo cambio en las últimas dos décadas. Hasta hace poco, el cirujano estaba interesado y dedicado exclusivamente a la atención profesional del paciente, sin considerar ningún factor económico que pudiera influir en las decisiones. En la formación del médico en las Facultades, se enseña mucha anatomía fisiología, patología médica o quirúrgica, se insiste en la necesidad de pensar constantemente en el bienestar del paciente, pero no se enseña en ninguna parte la organización de un servicio clínico, la implementación de la eficiencia en el quehacer médico y menos en la necesidad de cuidar cada vez más el aspecto económico que involucra nuestra actividad.

Este verdadero divorcio entre la actividad clinica y la administrativa tiene funestas consecuencias, en especial en Hospitales que tengan una importante o total dedicación a la academia. En Chile existen solo 3 hospitales universitarios, mientras que un gran número de Hospitales Ministeriales tienen convenio con diferentes Universidades. Si este divorcio persiste y los cirujanos que acceden a puestos directivos no se involucran en el proceso administrativo, pueden ocurrir algunos hechos con serias consecuencias:

a) Para la mayoría de los administradores de Hospital, la investigación clínica no es prioritaria, ya que solo produce gasto del sistema financiero. En la actualidad las decisiones quirúrgicas se toman basadas en las evidencias cientificas y si no hay investigación, no hay progreso quirúrgico.

b) La docencia pierde su trascendencia, ya que esta actividad académica también es vista como una carga económica.

c) Se pierde el contacto humano y personalizado, ya que desde el punto de vista administrativo los pacientes son solo "clientes".

d) El manejo exclusivamente administrativo de un Centro Hospitalario logra paulatinamente eliminar la discusión o el disentimiento, no se tolera la discrepancia y se termina en decisiones unipersonales que no siempre son adecuadas.

Frente a esta importante irrupción del aspecto económico administrativo en la Salud y en la Cirugía en forma especifica, los Directores y Jefes de Servicios Clínicos con actividad universitaria, deben conocer y profundizar lo que se entiende por "Gestión Clínica en Cirugía”, ya desde los años 90 estos conceptos de autofinanciamiento, autogestión y asignación de recursos de acuerdo a compromisos de gestión han impactado profundamente la administración de un Servicio o Departamento de Cirugía. Por gestión clínica se entiende el conjunto de procesos que cumplen en forma eficiente una atención integral de un paciente. La introducción de los programas GES o AUGE son una clara indicación de la necesidad de administrar racionalmente los recursos de la salud, que siempre son insuficientes. Se debe desterrar la ignorancia y la variabilidad clínica para dar pasó a decisiones basadas en la mejor evidencia cientifica disponibles (mediante protocolos en guías clínicas) y con el menor costo económico posible. Por lo tanto este nuevo concepto de "cirujano gestor" es vital para el futuro desarrollo de la especialidad, principalmente entre los líderes quirúrgicos. De esta manera, de ser cirujanos dedicados a la práctica profesional guiados por un Jefe respetado por sus cualidades técnicas, se debe virar al tratamiento integral del paciente, basado en los aspectos clínicos, requerimientos tecnológicos, rapidez en el diagnóstico y evaluación del costo total de la prestación quirúrgica.

Los Directores de Departamento, Jefes de Servicios Clínicos Universitarios serán los responsables de la moderna motivación para el progreso personal, estudio y capacitación de sus médicos jóvenes. Deberán pasar de ser solo Jefes de Servicio a gestores de sus Unidades, protocolizando los procesos, mejorando la 
EDITORIAL

calidad de la atención clínica, profundizando la relación médico-paciente y logrando la satisfacción de sus pacientes. Se deberá exigir que cada cirujano en la consulta de policlínico solicite los test diagnósticos más adecuados y rentables y que indique el tratamiento que más beneficios le otorgue al paciente. También los Jefes de Servicio deben cuidar y evitar que algunos cirujanos jóvenes se cieguen por las novedades o grandes tecnologías de moda. Me parece que es deber fundamental de los dos grandes Hospitales Universitarios evaluar las nuevas técnicas y proponerlas al país si son adecuadas, o comentar que su uso no se justifica.

En la actualidad un Jefe de Servicio debe cuidar con gran esmero el "recurso cama”, que es cada vez más escaso tanto por el aumento de la población, el envejecimiento de la misma y el escaso crecimiento de los recursos en Salud. Una buena gestión clínica de la Jefatura hará que el uso de la cama se evalúe en función a la complejidad de la técnica que se va emplear, el tiempo de su recuperación, y todos los cuidados adicionales que se requiera.

En nuestro Departamento, el promedio de estada hospitalaria era de 10 días en los 80, siendo para una colecistectomía de 4 días. En la actualidad el promedio de estada es de 3,1 días y la colecistectomía de 1,2 días.

Finalmente, para que todos estos aspectos puedan ser realizados por las Jefaturas de Servicio, se requiere de la información. En el siglo XXI información es poder y permite realizar una gestión clínica eficiente para poder no solo realizar, sino evaluar y corregir lo deficitario. Esto significa que cada Jefe de Servicio debe contar con un cuerpo de mandos medios confiables y actualizados para realizar el trabajo clínico.

En resumen, un Director de Departamento o Jefe de Servicio debe ser un líder en Gestión Clínica, para lograr un desarrollo sustentable y eficiente de su Servicio Quirúrgico.

\author{
Dr. Attila Csendes J. \\ Profesor Titular \\ Departamento de Cirugía \\ Hospital Clínico Universidad de Chile
}

